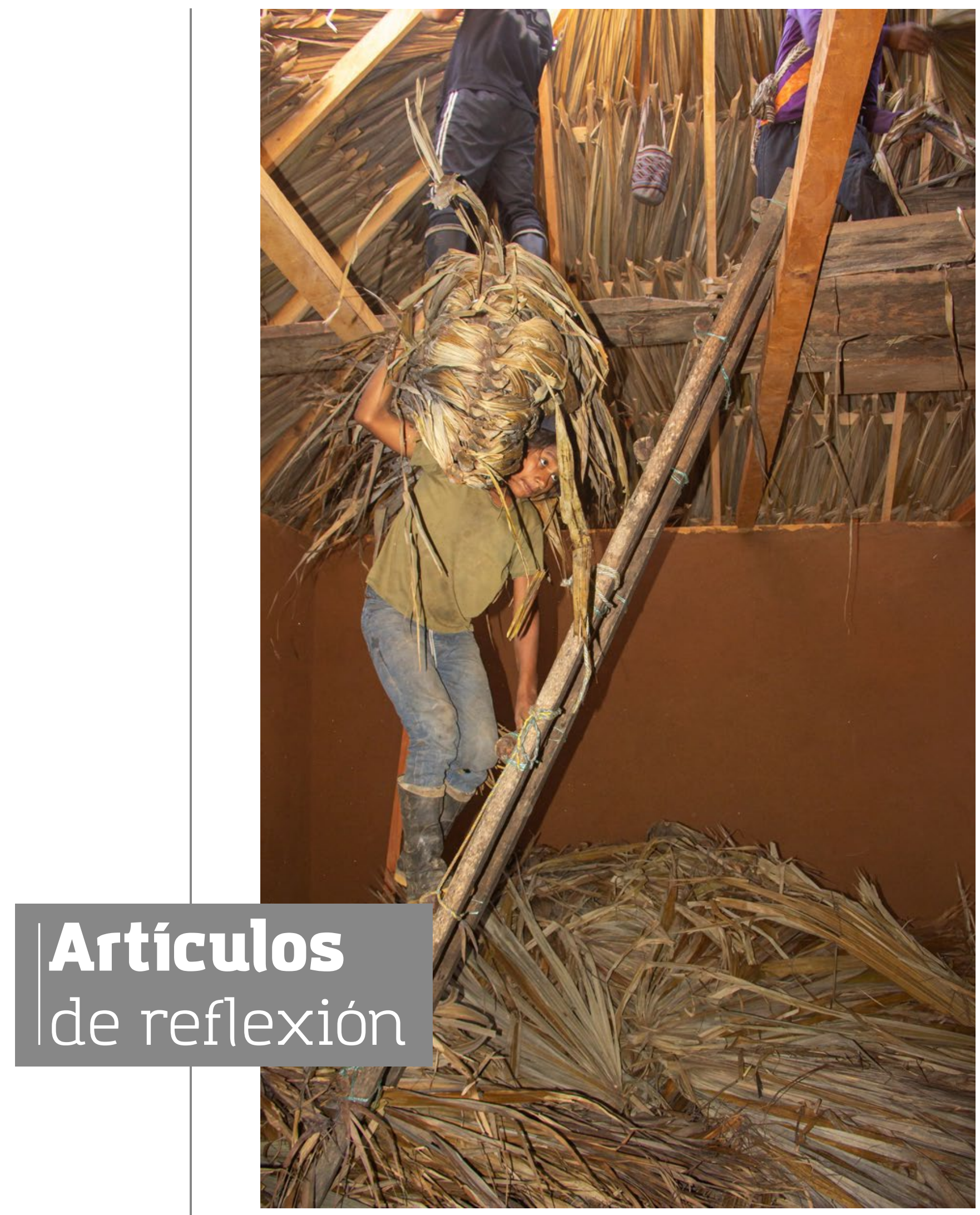




\section{Narrativas comunitarias en la construcción del imaginario social. Aproximaciones al relato como recurso vivo de la memoria colectiva}

\section{Community narratives in the construction of the social imaginary. Approaches to the story as a living resource of collective memory}

DOI: https://doi.org/10.18566/comunica.n46.a06

Recibido: 12 de junio de 2021

Aceptado: 3 de noviembre de 2021

\section{Resumen}

Este trabajo intenta establecer la composición de las propiedades discursivas de la narrativa para describir y profundizar en algunas conexiones que el imaginario social plantea. Desde esta perspectiva, el relato, que se desprende de la narrativa, aparece como el recurso vivo, dinámico y oralizado que finca la naturaleza de los hechos y los anida en la memoria de la colectividad social. En su estructura, el relato se configura a partir de discursos que responden a una vigorosa tradición oral, en la cual se plasman los referentes identitarios de las comunidades. A su vez, esta formulación pretende también explicar cómo se tejen los relatos en la conformación de una serie de creencias, deseos y recreaciones culturales. Dicho conjunto de procesos se condensa en la categoría del imaginario social. La particular conexión de la narrativa y su extensión en el relato, así como la articulación de las referencias históricas soportadas por la memoria colectiva de un espacio, son el alimento permanente de la constitución de un imaginario, es decir, de un imaginario emergente.

\section{Ismael}

\section{Colín Mar}

Doctor en Ciencias Sociales de la Universidad Autónoma del Estado de México. Profesor-investigador de la Universidad de Ixtlahuaca CUI.

ismael.colin@uicui.edu. mx; https://orcid.org/00000001-6994-8535

\section{Palabras clave} Narrativa, Relato, Discurso, Memoria, Imaginario social

\section{Keywords}

Narrative, Story, Discourse, Memory, Social imaginary. 


\section{Abstract}

This work tries to establish the composition of the discursive properties of the narrative to describe and deepen some connections that the social imaginary poses. From this perspective, the story, which emerges from the narrative, appears as the living, dynamic and oralized resource that establishes the nature of the facts and nests them in the memory of the social community. In its structure, the story is configured from discourses that respond to a vigorous oral tradition, where the identity references of the communities are reflected. At the same time, this formulation also aims to explain how stories are woven into the conformation of a series of beliefs, desires and cultural recreations. This set of processes is condensed into the category of the social imaginary. The particular connection of the narrative and its extension in the story, as well as the articulation of the historical references supported by the collective memory of a space, are the permanent nourishment of the constitution of an imaginary, that is, of an emerging imaginary.

\section{Introducción}

El descubrimiento de las historias personales y comunitarias a través de los relatos ${ }^{1}$ es un propósito complejo en el quehacer de la investigación social, sobre todo si se pretende desvelar las circunstancias que coexisten con el relato y el discurso, así como las manifestaciones sociales que expresan. Una visión interdisciplinaria podría ayudar a encontrar rubros en la construcción metodológica para la recuperación del material incrustado en todo el armazón de redes socioculturales de los espacios en estudio. Por ello, una de las primeras intenciones de este trabajo es buscar las conexiones conceptuales que se hallan en la propuesta lingüística de las narrativas, la cual, a su vez, supone también una formulación epistémica, en cuanto la constitución de objeto de estudio.

Por otro lado, el tema implica asimismo buscar las conexiones con la categoría del imaginario social, pero primero intenta establecer la composición de las propiedades discursivas de la narrativa. Desde esta perspectiva, el relato aparece como el recurso vivo, dinámico y oralizado, ${ }^{2}$ que finca la naturaleza de los hechos y los anida en la memoria de la colectividad social. En su estructura, el relato se configura a partir de discursos que responden a una vigorosa tradición oral, en la cual se plasman los referentes identitarios de las comunidades.

1 En esta idea, Ricoeur (2014a) ayuda a establecer que, en su estructura, tanto el relato ficticio como el relato histórico tienen una narrativa común.

2 Este dinamismo se debe a la manera en que se presenta como flujo constante: aun cuando lleva una línea discursiva, el cuerpo del relato se adereza con múltiples formas interpretativas de la misma comunidad o localidad. Precisamente, este apartado introductorio plantea como parte sustantiva las propiedades internas del relato, así como dentro de un conjunto de relaciones que se tejen a su alrededor. 
Con esta intención, se intenta identificar las conexiones conceptuales que tejen los relatos como oralidad en la conformación de una serie de creencias, deseos y recreaciones culturales. Dicho conjunto de procesos se condensa en la categoría del imaginario social. La particular conexión del relato convertido en narrativa, así como la articulación de las referencias históricas soportadas por la memoria colectiva de un espacio, es el alimento permanente de la constitución de un imaginario, es decir, un imaginario emergente; que Castoriadis (2005) apunta como "la emergencia de la subjetividad".

\section{La génesis del relato}

Una de las primeras preguntas de este acercamiento es la siguiente: ¿desde dónde se piensa el relato?, o bien, ¿cómo se constituye esta expresión en un eje discursivo del habla?; así como la propia articulación en los contextos sociales de esta figura discursiva, que lleva a discurrir su constitución conceptual, a la vez que tiene rasgos de una mirada epistémica. Quizá esta pregunta obliga a posicionarse conceptual y epistémicamente para abonar en la construcción de un objeto de estudio.

En este sentido, una perspectiva tiene que ver con su aparición en el terreno de lo empírico, en aquello que integra el relato. Es decir, como un campo de investigación social, donde se conforman su expresión relacional y vínculo social para ser considerado como un tema de investigación. Así, en esta idea, la génesis del relato no alude únicamente al surgimiento del relato en su expresión real y empírica, sino también a su construcción conceptual y referencia teórica para ampliar su estudio.

Se parte, entonces, de dos posturas que aportan ideas a la explicación del relato en cuanto configuración de un discurso que se somete a la articulación de la palabra escrita o hablada; a la luz de estas dos formulaciones que este texto pretende relacionarse. Amén de aquello, tampoco se establece una marcada diferenciación sobre las concepciones que se mencionan, solo que, particularmente, una de ellas permite configurar una explicación más coherente con los propósitos de este trabajo.

En el primer planteamiento, el acto narrativo se manifiesta como del sujeto, en virtud de que el relato permite re-hacerse, re-constituirse al sujeto, y, por lo tanto, comprender su mundo de vida a través de un acto interpretativo.

La vida viene a ser, entonces, además de un tejido de historias contadas, el campo de una actividad constructiva en la que reencontramos la identidad narrativa que nos constituye a la luz de los relatos que nos propone nuestra cultura (Ricoeur, 2014a, p. 24). 
En el segundo, las prácticas discursivas constituyen el sujeto. Aquí el sujeto no se re-hace: más bien desaparece en la escritura, por cuanto el sujeto es también un campo discursivo

No habría habido, por tanto, inicio; y en lugar de ser aquel de quien procede el discurso, yo sería más bien una pequeña laguna en el azar de su desarrollo, el punto de su posible desaparición (Foucault, 2005, p. 11).

Cuando se hace mención del relato, fundamentalmente se parte del relato histórico, recuperando la distinción que hace Ricoeur (2014a) para los tipos de relato, aunque después abona en la idea de la narrativa común. La caracterización de estas discursividades es muy amplia y requiere, en primera instancia, un esfuerzo de recopilación de este discurso, a través de la configuración de los relatos que circulan como vox populi; en segundo lugar, a partir de una descripción del contexto donde se recupera, así como los referentes que involucra para significar el argumento central de este discurso y, finalmente, interpretar los contenidos discursivos del relato. En este armazón, el relato y la memoria aparecen como dos procesos continuos, conectados el uno con el otro, alimentándose entre sí.

... el discurso no es simplemente aquello que traduce las luchas o los sistemas de dominación, sino aquellas por lo que, y por medio de lo cual, se lucha, aquel poder del que quiere uno adueñarse (Foucault, 2005, p. 15).

Ante estas dos perspectivas, la primera de ellas ofrece posibilidades explicativas en el interés de este trabajo, ya que la configuración de los procesos y manifestaciones socioculturales está siempre relacionada por una elaboración discursiva, ${ }^{3}$ más o menos coherente, sobre los acontecimientos pasados y presentes, en los que el sujeto y la comunidad se encuentran. La forma en la que se perciben los acontecimientos ofrece un panorama que se multiplica en todo el sistema de creencias de un determinado lugar. Es decir, la elaboración discursiva de quienes integran la comunidad está representada por una serie de imágenes de los hechos que se manifiestan con toda su multiplicidad de significado.

En sentido estricto, el relato se conforma de una narrativa o, como menciona Ricoeur (2014a), de una "estructura narrativa", la misma que está integrada por un discurso, o bien por modelo de discurso. Una de las partes sustanciales del relato, en sus dos acepciones, es la frase narrativa, aspecto de vital importancia para establecer la correlación de temporalidad entre pasado y futuro. Dicho con otras palabras, "es una de las descripciones de una acción en función de aquellos acontecimientos posteriores que desconocían los agentes" (Ricoeur, 2014a, p. 90). Este juego de historicidad supone que los actos que ocurren no se nombran ni configuran en el momento, sino hasta
3 Se entiende desde esta perspectiva que el discurso se refiere a los actos del habla, del lenguaje de la elaboración de la palabra como una estructura verbal. 
después; por tanto, se intenta definir desde la posición de uno haciendo referencia al otro.

Una frase narrativa, por tanto, es una de las descripciones posibles de una acción, pero no la única. Podemos describir una acción en función de sus motivos, de sus intenciones o de sus fines (...) El hecho de que Aristarco se anticipase, en el año 270 antes de nuestra era, a la teoría publicada por Copérnico publicada en 1543 no podía apreciarse en los tiempos de Aristarco (Ricoeur, 2014a, pp. 90-91).

El relato construido desde diferentes perspectivas proscribe la homogeneidad de los procesos sociales contemporáneos. Es decir, la narrativa a través de un relato elaborado permite y da cuenta de la heterogeneidad social misma que aloja la diversidad y el actuar sociocultural de un espacio determinado. Aun experiencias similares pueden tener un proceso distinto de interpretación y comprensión del sujeto.

La configuración de un relato es la expresión del rasgo histórico en él, sea desde la idea del relato histórico o ficticio, donde los personajes cumplen y se desarrollan en el acto histórico. Cuando se habla de los grandes acontecimientos, ${ }^{4}$ en esta idea se pretende ubicar la característica coyuntural de los hechos históricos. Pero en términos concretos, la reducción de los hechos a un solo aspecto coyuntural evade a todos los elementos que intervienen en su propia naturaleza, y solo se los toma en ese momento dada su importancia.

A saber, algunos autores (Lyotard, 1998) plantean que la humanidad se había configurado por medio de grandes relatos, los cuales ahora, en esta época, adquieren una nueva interpretación, diferente a la que tuvieron cuando habían surgido.

\section{De los grandes relatos al relato cotidiano}

Cuando se propone la idea de los grandes relatos, se asume que hay una gran diversidad de historias locales, regionales y nacionales que transversalmente tejieron las historias de muchos pueblos, o bien que directa o indirectamente se manifestó una relación que implicara su conexión. Por ello, los hechos históricos están respaldados en una narrativa que por antonomasia establece la presentación de un discurso, ${ }^{5}$ el cual los objetiva y los convierte en un elemento real y constante de las historias sociales de la humanidad.

... cuando se habla del discurso del neoliberalismo (...) el término "discurso" no se refiere exclusivamente al uso que hacen del lenguaje los pensadores o los
4 Esta expresión se recupera del debate entre las posturas antinarrativistas que menciona Ricoeur (2014a); sin embargo, no se reduce a esta expresión, ya que, como comenta el mismo autor, cuando se habla de "grandes acontecimientos", se hace alusión a los papeles que desempeñan "grandes hombres", lo que indica un desplazamiento de una historia política a una historia social, en la cual el centro de los hechos es el sujeto.

5 Cuando se utiliza el término discurso para referir la composición del relato y su propia narrativa, el trabajo se adscribe a la perspectiva que plantea Ricoeur (2014a). Es decir, como estructura narrativa donde la narración plantea un modelo discursivo homogéneo para el relato histórico y ficticio. 
políticos neoliberales, sino también a las ideas y filosofias que ellos sustentan y divulgan (Van Dijk, 2001, p. 12).

En esa condición, los relatos cotidianos se inscriben en un relato más extenso que se conoce como la historia de un lugar. No se excluye: muy por el contrario, se adapta y retoma aspectos que le dan singularidad a ese espacio local, que se conecta en un ir y venir de la historia general. En un sentido más relacional, la expresión del relato considera por extensión un correlato que se desprende de la aparición del primero. La relación que manifiesta el primero sobre las situaciones y condiciones de un contexto social determinado acompaña otras características dependientes del segundo. Así, en el contexto, por ejemplo, del surgimiento de las ciencias sociales básicamente europeizantes y posteriormente estadounidenses, se convirtió en un correlato "civilizatorio de la pérdida del dominio político y económico indiscutido de occidente en el mundo" (Wallerstein, 1996, p. 57).

Si bien los grandes relatos refieren a la presentación de acontecimientos ${ }^{6}$ que contienen una narrativa discursiva, son también la referencia a la que se pueden adscribir las historias locales y personales, es decir, desde un punto de vista del sujeto. Por ello, las narrativas locales de los pueblos tienden a relacionarse con una narrativa mayor de un discurso totalizante, como anteriormente se mencionó (Lyotard, 1998; Wallerstein, 1996), en el cual las conexiones colaterales de estos discursos comunitarios ofrecen un mapeo de lo que se configura de manera general, esto es, en el escenario de la vida política regional, nacional e internacional, según sea el caso.

En el marco de estas consideraciones, el relato, y por extensión el discurso, ofrece una perspectiva del estado de cosas con el que puede relacionarse un determinado hecho social. Cuando se hace referencia en este sentido a las narrativas comunitarias, se intenta distinguir esa correlación de los procesos simbólicos que suceden en un contexto y que estimulan la construcción de un imaginario social comunitario.

\section{Contar la historia del lugar}

Nuestros referentes del lugar donde crecimos, pasamos una época de nuestra vida o habitamos actualmente son recuperados a partir de una selección que, en suma, representa el olvido (Jelin, 2002). Por ello, el relato se constituye como una forma lingüística que se ciñe al contexto del sujeto de su importancia y validez sociocultural; sea porque su repetición reconstruye las prácticas comunitarias que cohesionan la localidad o el espacio.
6 Aquí el acontecimiento es entendido con su carga discursiva, donde la narrativa no desaparece, sino que, más bien, adquiere una profunda relevancia, alejado de las pretensiones objetivistas. 
Pasar por una vida, dice Ochs (2001), en la cual no haya narraciones, una vida sin decir a los demás lo que nos ocurre o lo que les pasa a otros, no contar lo que ha pasado en la vida de cada uno, o lo que hemos leído o visto en nuestra vida cotidiana es verdaderamente inimaginable. Por ello, contar la historia de un lugar a través de los relatos resulta de vital importancia para configurar la identidad y los rasgos culturales de una comunidad.

La forma narrativa ha sentado precedentes en la historia de la humanidad, sea como relato ficticio o bien como relato histórico. Cuando se recupera la información que expresaba Heródoto (1999) en Los nueve libros de la historia, se reconoce que la capacidad descriptiva de lo que ocurrió en las guerras Púnicas y del Peloponeso es de gran relevancia para conocer las estrategias de lucha y las prácticas de socialización que se manifestaban en el terreno de la conquista, de la imposición de estructuras de organización social y política en otros espacios apenas desconocidos por los conquistadores.

Como género fundamental que organiza los modos en que pensamos e interactuamos unos con otros, la narrativa comprende, sin embargo, un enorme espectro de formas discursivas que incluyen géneros tanto populares como cultos. La forma más importante y universal de la narrativa no es el producto de la musa poética, sino de la conversación corriente (Ochs, 2001, p. 271).

Así, las narrativas, en los textos escritos y orales, son una forma, pero invariablemente se pueden encontrar otros modos de representación apoyados en expresiones cinéticas, pictóricas, musicales (Ochs, 2001). En muchos casos, los movimientos corporales delatan una narrativa que se inscribe en el contexto de un carnaval, una mojiganga o una danza particular de su región o localidad. Sin embargo, no siempre la narrativa se expresa de un modo único: puede involucrar más formas, de las cuales se enriquece el relato.?

La historia del lugar supone la presentación de un relato que conecta con una lectura del hombre, su contexto y su propia historia personal. El tiempo narrativo es tiempo humano en la perspectiva de Ricoeur (2014b); es a partir de esta consideración como el ser humano aprehende el tiempo a través de la narrativa.

\section{Contarse a sí mismo}

Es a través de los actos humanos como se relata y aparece la posibilidad de aprehender la historia, configurarla para dar cuenta de los hechos que significan y detallan la vida social. La narrativa cumple una función importante, ya que "le da sentido de continuidad de uno mismo y la sociedad" (Ochs, 2001, p. 280).
7 Para W. B. Gallie, la composición narrativa está integrada por el relato (story), ya que la historia es una forma particular de relato, también conocido como historia contada. El relato que produce la historia es llamado history. Ambos se refieren a algún logro o fracaso de los hombres que viven en sociedad (Gallie, 1968, citado en Ricoeur, 2014a, p. 94). 
Concretamente, no existe separación entre quien cuenta la historia del lugar y lo que todos cuentan de ese lugar donde han ocurrido acontecimientos. Hay una parte que se construye de manera personal, en la cual existe una conexión con una versión comunitaria que respalda la idea general del hecho. Lo cierto es que la recuperación oral de la persona se da siempre en condiciones propias a su contexto individual, sin olvidar la parte extensiva del acontecer social de la comunidad. "Lo que pensamos de nosotros mismos y de los demás está influido por el contenido del mensaje de los relatos narrados en conjunto y por la experiencia de trabajar juntos para construir una narración coherente" (Van Dijk, 2001, p. 273).

El ser humano busca en buena medida fortalecer los lazos que lo unen con su lugar de origen o con la propia residencia; por ello, se acompaña de la jerga narrativa de los lugareños para establecer la convivencia y la conveniencia. La incorporación de los relatos a través de una serie de narrativas hace evidente esta participación del sujeto colectivo. La memoria en este caso tiene un alto valor: permite recrear los eventos significativos para el sujeto, tanto en términos personales como sociales, aun cuando existen relatos que son negados por las instituciones del Estado como una estrategia represiva para legitimar una u otra narrativa manifestada en los discursos políticos, y que posteriormente se convierten en historias negadas y memorias abusadas, en el sentido que plantea Todorov (2013).

Ninguna institución superior, dentro del Estado, debería poder decir: usted no tiene derecho a buscar por sí mismo la verdad de los hechos, aquellos que no acepten la versión oficial del pasado serán castigados. Es algo sustancial a la propia definición de la vida en democracia: los individuos y los grupos tienen el derecho de saber; y por tanto de conocer y dar a conocer su propia historia, no corresponde al poder central prohibírselo o permitírselo (Todorov, 2013, p. 19).

Al margen y dentro de los propios relatos del sujeto, se tejen narrativas que le corresponden al propio individuo como actos de reconocimiento de sí mismo dentro de la comunidad. Contarse a sí mismo en el marco de la dinámica sociocultural del lugar es un acto de reconocimiento identitario fundamental para la participación activa en las actividades que se desarrollan en la propia comunidad.

Contarse a sí mismo aparece, entonces, como una posibilidad de encuentro con los relatos de la comunidad, pero también con la idea de cómo me encuentro (o desencuentro) con esa narrativa. Un espejo que confirma la identificación con los objetos, las personas, los rituales y las prácticas comunitarias. Este juego psicológico de encontrarse en el relato, sea de manera activa o pasiva, convierte al sujeto y a la misma acción en una alternativa de emancipación. 


\section{Relato y memoria}

Como ya se estableció líneas arriba, la forma en la que aparece el relato y particularmente configura la existencia del sujeto (desde la postura que se planteó al inicio) confirma la relación de este con su contexto y su capacidad recreacional para sustentar los procesos identitarios; o bien como parte de su identidad narrativa, la misma que le sirve para reconstituirse en el espacio y fundamentar los orígenes del relato en conjunción con la memoria. Aquí el elemento de la memoria se acoge a los actos del recuerdo, y del olvido, como un continuum de recuperación de los hechos que acontecieron y que fueron en mayor o en menor medida trascendentes para el sujeto.

Inscribir los hechos desde la recuperación oral es un recurso que se presenta en las historias locales, en las cuales la comunidad recupera para sí los eventos de trascendencia social, política, cultural, religiosa, etc. Tal condición cohesiona y legitima el curso de los acontecimientos que se desarrollan en los espacios comunitarios. Esta idea existe paralelamente a la historiografía oficial, donde el carácter estricto del armazón histórico no admite otra historia, es decir, otra narrativa.

No obstante, cuando se habla de los referentes históricos que permiten establecer comparativos, es inevitable recurrir a la memoria comunitaria como un eje que articula las relaciones socioculturales de quienes integran un determinado lugar. En los recursos de la memoria, menciona Jelin (2002), el individuo solo trae lo que solventa su existencia, y excluye de facto todo aquello que no quiere recordar, o bien como producto del olvido. La memoria colectiva inserta en la dinámica comunitaria subvierte los procesos de resistencia, expresados en una manera de narrar los hechos que acontecieron en ese lugar, y la transmisión oral se convierte en una práctica de resistencia al poder (Jelin, 2002).

En sentido estricto, recordar y olvidar son elementos de la memoria, y se manifiestan simultáneamente, solo que, en el intento de recordar una situación, se excluyen aspectos de la historia relatada y únicamente se incorporan al relato aquellos retazos de la historia que configuran un proceso de significación, o bien para estimular la construcción identitaria. Las narrativas incrustadas como expresión propia del relato histórico acuden con regularidad a los acomodos de la memoria. Aquella que se convierte en un reservorio de situaciones y acontecimientos comunitarios, en lo cual el recuerdo y el olvido son formas constantes de esta recuperación oral discursiva.

Todo texto oral es efimero y fluido, repleto de silencios y fragmentaciones, gestual y corporal. La voz anónima, colectiva, está hecha de memorias y olvidos, de reciclajes y misturas, de guiños, complicidades y miradas (...) La memoria 
tanto colectiva como individual es una memoria también activa que revela un funcionamiento cambiante y creador. En ese sentido el pasado no es estático, está siempre en permanente reelaboración (Cocimano, 2006, pp. 24-25).

Por otro lado, ante las nuevas narrativas que surgen de la cultura audiovisual y electrónica, la oralidad se plantea como una forma de invención de los discursos y los espacios comunitarios (Cocimano, 2006); es decir, se presenta una dinámica renovadora que permite la permanencia de esos referentes simbólicos que cohesionan la historia local.

La fortaleza de la tradición oral comunitaria representa un soporte que incentiva y protege el sentido identitario de los espacios, a la vez que territorializa los hechos y las historias pasadas para darles vigencia en un discurso contemporáneo; también busca permanencia de los discursos orales incrustados en las narrativas comunitarias. En ellas los rituales que se expresan en mecanismos gestuales, corporales y verbales conforman una dramatización y teatralización de la oralidad. "Esta articulación de lenguajes o códigos, implica que la oralidad se promueve bajo determinadas condiciones que en unos casos pueden remitir a las temporalidades profanas de lo cotidiano y, en otros, a circunstancias de carácter ritual" (Quintanilla, 2003, p. 29).

\section{La impronta del relato}

Desde hace tiempo, el individuo se planteó la recuperación de sus acciones a través de narraciones, unas veces plagadas de fantasía, otras tantas de realismo, y en la mayoría de las veces con una combinación de estas dos formas significativas:

Los cuentos de origen siguen la misma pauta. Son estas narraciones sencillas de fuerte sabor festivo que se encuentran en los límites de los verdaderos mitos y los relatos producidos por el mero placer de la invención fabulosa (...) son historias en las que los animales, las plantas, los minerales, el hombre mismo inician su existencia a partir del último toque de una divinidad, de la última acción de una aventura, de la última causa que lleva al efecto global de la obra completa (López Austin, 2012, p. 33).

Esta es quizá la expresión activa del relato y la memoria, donde se imprime el vigor de los hechos sociales. Su manifestación provee de un sinfín de expresiones del actuar humano que se impregnan en la memoria y son recuperadas en cada acto de recreación comunitaria en rituales y tradiciones culturales en las cuales la participación del sujeto es muy activa y dinámica. Aunque las narrativas expresadas en los relatos históricos comunitarios tienen una vigencia, hay en ellos una fuerte recuperación de los hechos 
pasados, que son recreados una y otra vez. Como la memoria alimenta estos vaivenes históricos, el relato queda impreso en las recreaciones y en las historias fantásticas convertidas en mitos y leyendas, así como en cuentos y fábulas que representan la vida comunitaria.

En este sentido, la oralidad constituye una alternativa para narrar los acontecimientos de la comunidad, incrustados en una gran variedad de mitos, ritos, cuentos, leyendas, siempre desde la perspectiva del poblador, desde dentro de su cultura. Por ello, una de las posibilidades narrativas desde siempre es rescatar del olvido todas las prácticas culturales que tienen un significado particular, ya que tejen la urdimbre sociocultural de la comunidad. Y en sentido estricto, lo que se preserva del olvido accidental o incomprensivo son aquellos referentes que significan y le dan a la memoria cierta relación con el imaginario social (Quintanilla, 2003).

Así, cuando se hace mención de la impronta del relato, se hace referencia a la posibilidad de que la estructura narrativa selle los actos para que sean recuperados con esa particular impresión de su propio origen, aun cuando la recreación se presente en otro momento y otras opciones de contexto. La misma posibilidad de sellar los actos consiste en hacer válidos los aspectos históricos que permitieron el desarrollo de aquellos tal y como acontecieron en un pasado; revivirlos como un hecho simbólico del recuerdo se convierte en una intempestiva aparición de la memoria viva del relato.

\section{Narrativa e imaginario social}

Las características descritas anteriormente se relacionan profundamente con la conformación del imaginario social, ya que los relatos expresan un discurso que se constituye de los deseos, creencias y aspiraciones de los sujetos. Esta expresión discursiva forma parte de la narrativa que el propio sujeto articula como voz, como movimiento, como simbolo, y como una expresión de la multiplicidad de interpretaciones que hace desde su contexto social y en su contexto social.

Con esto, la memoria aparece como un vehículo para recuperar aquello que representó y sirve como fundamento para reactivar los hechos pasados convertidos en identidades narrativas, en diálogos con su presente, con las nuevas circunstancias que el entorno social manifieste.

La memoria posee rupturas y quiebres, se va transformando en imaginario social, consecuencia de la relación de las comunidades tradicionales con prácticas y discursos de la modernidad. En este sentido, la oralidad actualiza 
aquellos sentidos todavía necesarios para una determinada comunidad, pero olvida aquellos que ya no cumplen ninguna función (Cocimano, 2006, p. 25).

En esta acepción, el ser humano, en su primera necesidad social, percibió un mundo ordenado naturalmente, donde la noche y el día marcaban el tiempo y la contingencia del mismo establecía la ruta del quehacer social cotidiano. La caza, la pesca y la recolección estaban supeditadas a los ritmos que el tiempo ofrecía; es decir, dada la inseparable manifestación del tiempo y su vínculo con el espacio, establecían cómo el hombre debería cohabitar con una serie de fenómenos ligados a la transformación natural.

El cambio de prácticas sociales estaba asociado a la premisa arriba mencionada. Gradualmente, el hombre adquirió habilidades de adaptación y control de la naturaleza, ciertamente marcada por una división natural del trabajo, cuya asignación de roles se establecía por el sexo y la edad. En esta idea, "la concepción mítica unifica los principios ordenadores del mundo dando las mismas leyes cósmicas a lo social y a lo natural. Lo logra por medio de juegos de proyecciones que uniforman los procesos de todo lo que existe" (López Austin, 2012, p. 34).

A este respecto, el tiempo es a la vez una creación imaginaria y con ello el sistema de organización resulta aparentemente ordenado; así, un pueblo estaba determinado a resolver sus necesidades básicas (como la subsistencia), satisfacer las pulsiones sexuales y explicar sus instituciones sociales, sus creencias y su mitología (Lévi-Strauss, 1989).

La conformación de grupos de orden primario para desarrollar habilidades de caza, pesca y recolección manifestó gradualmente una posibilidad latente de vivir juntos, o bien en lugares cercanos, en algunos espacios que posteriormente serían acondicionados a las necesidades de estos pequeños grupos. Hay una intención evidente del hombre por concebir una mayor capacidad de organización, asumida inevitablemente por la sinergia compartida del territorio, del tiempo y del mismo individuo. Habiendo controlado y asumido un rol que ejerce un poder instituido, el individuo adopta ahora la pretensión de ordenar su mundo en consonancia con el mundo natural que lo rodea. Las representaciones sociales establecidas por el sujeto y su relación interna con el grupo de alguna forman crean o van construyendo un referente de organización que puede ser el sustento de organizaciones más complejas, como asevera Baczko en la siguiente idea:

A lo largo de la historia, las sociedades se entregan a una invención permanente de sus propias representaciones globales, otras tantas ideas-imágenes a través de las cuales se dan una identidad, se perciben sus divisiones, legitiman su poder 
o elaboran modelos formadores para sus ciudadanos tales como el "valiente guerrero", el "buen ciudadano", el “militante comprometido" (2005, p. 8).

Esta versión latente de una forma de organización es una de las manifestaciones que el hombre utilizó; sin embargo, no es la única con la cual se asociaba grupalmente la construcción de su realidad: antes estuvo mediada por la instauración de mitos, asociados a objetos y fenómenos naturales, donde la explicación o certidumbre era la fuente de un poder inmanente al sujeto, a la capacidad de organización que de ello emergía. No resulta exagerado decir que la fuente de construcción social, en el sentido del orden, estaba respaldada por una serie de factores de índole mítica, como lo menciona Lévi-Strauss:

... esos pueblos que consideramos totalmente dominados por la necesidad de no morirse de hambre, de mantenerse en un nivel mínimo de subsistencia en condiciones materiales muy duras, son perfectamente capaces de poseer un pensamiento desinteresado, es decir, son movidos por una necesidad o un deseo de comprender el mundo que los circunda, su naturaleza y la sociedad en que viven (1989, p. 37).

Ese intento por explicar el mundo de acuerdo con sus propias posibilidades los dotó de unas habilidades intelectuales que fundamentaron gradualmente la conformación de sociedades más complejas en términos de organización. La creación imaginaria a través de pensamiento mítico permitió establecer un sistema de significaciones que explicaban su mundo, y de ahí la articulación religiosa con conexión en todo el armazón cultural. Se parte de la idea de que los pueblos ágrafos ${ }^{8}$ manifestaban un principio de imaginación colectiva que fortaleció los deseos de organización y creación de instituciones.

En este tenor, vale también retomar las aportaciones de Freud, cuando establece la idea del animismo como forma de explicación de los pueblos ágrafos, caracterizándolos en una filosofía de la naturaleza, es decir, la forma como eran concebidos el mundo y la naturaleza (Freud, 1989, p. 103). Se distingue que la conceptualización del animismo estaba asociada al pensamiento mítico, y este representa una de las concepciones del universo, en la cual el mito reposa sobre elementos animistas y funda la primera explicación del hombre y su universo.

La creación imaginaria de estos pueblos, que se estableció anteriormente, representa en el animismo una singular conexión con el pensamiento mítico, ya que expresa un imaginario creativo para la configuración de sus sociedades y de la identificación colectiva de estos pueblos.
8 Este concepto es planteado por Lévy-Strauss para definir a los pueblos que existieron previamente a la invención de la escritura, en oposición al término pueblos primitivos, utilizado por Malinowski (LévyStrauss, 1989). 
El término que se ha manejado como imaginario se reconoce en este rastreo histórico como un articulador y conformador de realidades. Se partió de los pueblos ágrafos para fundamentar esta concepción y no arribar visiones infundadas, en un breve acercamiento para mostrar comparativamente cómo se fue instituyendo este concepto no solo en la historia de la teoría social, sino como explicación de aquella incesante búsqueda de símbolos que, apropiados por el sujeto, legitiman y multiplican una dominación o conjugan las relaciones de sentido y poderío (Baczko, 2005). Pero singularmente también cohesionan las identidades comunitarias y significan las relaciones que se tejen entre los individuos en los ámbitos personal y social.

Esta emergencia de la creación subjetiva como lo representa el imaginario da sustento legítimo a las prácticas sociales y opera en el terreno de la subjetividad colectiva, como apunta Castoriadis:

... la historia de la humanidad es la historia del imaginario humano y de sus obras. Historia y obras del imaginario radical, que aparece apenas existe una colectividad humana; imaginario social instituyente que crea la institución en general (...) y las instituciones particulares de la sociedad considerada (2005, p. 93).

Lo instituido en esta visión es la representación colectiva de la vida social; de ahí que la colectividad humana instaura el hecho de la creación constante de significaciones, y se puede citar una multiplicidad: desde las religiones, los héroes, los tótems, los tabúes, los fetiches, o bien de una complejidad mayor, como el Estado, la iglesia, etc.

La expresión del imaginario en términos reales se manifiesta en la práctica social; es decir, no hay tal práctica sin un sentido y este es una asignación del orden simbólico asumido por los sujetos que solo operan en el nivel del imaginario (Serret, 2001).

\section{Algunas consideraciones finales}

A la par de este esfuerzo por definir el armazón teórico-conceptual de las narrativas, va flanqueado por una pertinencia empírica de los conceptos y de sus propiedades. Es decir, esta propuesta reconoce que el mismo tejido conceptual permite incorporar ejes de análisis concretos de la realidad, que evidencian sus conexiones. Precisamente en esta intención se fundamentan los elementos teóricos que servirán para un análisis empírico posterior, pero que por su propia naturaleza (subjetiva) es necesario tejer la urdimbre o bien establecer un puente que facilite una explicación-interpretación de los vínculos que surgen en las narrativas comunitarias. 
Por otro lado, como objeto de estudio, la narrativa y las narrativas aparecen a los sentidos humanos como formas de representación sociocultural; es decir, los seres humanos configuran interpretaciones acompañados de su vida comunitaria, así como de un nivel de comprensión cultural que hace de su participación y colaboración con las prácticas sociales de la comunidad una estrategia de identificación y comprensión social. En relación con esta idea, existen dos visiones que complementan esta construcción teórica: la primera de ellas se basa en una perspectiva general de la historia comunitaria, es decir, cómo aparece en el contexto de una (narrativa) historia global (entiéndase regional, nacional e internacionalmente), cómo se relata y la forma en que el relato se hace extensivo para dar cuenta de los grandes relatos, incrustados en el imaginario histórico de los pueblos del mundo y de las comunidades. La segunda de ellas formula una descripción del sujeto que incorpora estos referentes narrativos, producto de relatos globales, a relatos personales e individuales, donde la conformación de imaginarios comunitarios es un acicate en la comprensión de sus prácticas socioculturales.

Finalmente, dos conceptos más que ayudan a esta construcción: uno se manifiesta a partir de la expresión viva del relato; este tiene que ver con el discurso tanto oral como escrito, en el cual su propia narrativa puede dar cuenta de las orientaciones e interpretaciones individuales y colectivas del armazón comunitario en que vive. El otro se relaciona con la memoria, aquel sustento de recuperación del pasado que reaviva una y otra vez los acontecimientos en un acto de recreación constante al traer en el presente una selección de hechos que forman la capacidad constituyente del imaginario social.

\section{Referencias}

Baczko, B. (2005). Los imaginarios sociales: memorias y esperanzas colectivas. Nueva Visión. Castoriadis, C. (2005). Figuras de lo pensable. Fondo de Cultura Económica.

Cocimano, G. (2006). La tradición oral latinoamericana, las voces anónimas del continente caliente. Araucaria, 8(016), 23-36.

Foucault, M. (2005). El origen del discurso. Fábula, Tusquets.

Freud, S. (1989). Tótem y tabú (Tercera edición). Alianza Editorial.

Heródoto. (1999). Los nueve libros de la historia. Conaculta.

Jelin, E. (2002). Los trabajos de la memoria. Siglo XXI Editores.

Lévi-Strauss, C. (1989). Mito y significado. Alianza Editorial.

López Austin, A. (2012). El conejo en la cara de la luna. Ensayos sobre mitología de la

tradición mesoamericana. Era, INAH, Conaculta.

Lyotard, F. (1998). La condición posmoderna. Cátedra. 
Ochs, E. (2001). La narrativa. En T. Van Dijk (Comp.), El discurso como proceso y estructura. Gedisa.

Quintanilla Coro, V. (2003). "Memoria e imaginario social: de la oralidad a la escritura" en Oralidad Anuario 12. Para el rescate de la tradición oral en América Latina y el Caribe. Oficina Regional de Cultura para América Latina y el Caribe de la Unesco, 25-33. Ricoeur, P. (2014a). Historia y narratividad. Paidós.

Ricoeur, P. (2014b). Tiempo y narración I. Siglo XXI Editores.

Serret, E. (2001). El género y lo simbólico: la construcción imaginaria de la identidad femenina. UAM, Azcapotzalco, Biblioteca de Ciencias Sociales y Humanidades. Todorov, S. (2013). Los abusos de la memoria. Paidós Contextos, Van Dijk, T. (2001). El discurso como proceso y estructura. Gedisa. Wallerstein, E. (1996). Abrir las ciencias sociales. Siglo XXI Editores, UNAM. 